\title{
"Eles têm o direito de expulsar-nos": a Nova Geografia Universal de Élisée Reclus
}

"Ils ont le droit de nous expulser" : La Nouvelle Géographie Universelle d'Élisée Reclus

"They have the right to throw us out": Élisée Reclus' New Universal Geography

"Ellos tienen derecho de expulsarnos": La Nueva Geografía Universal de Élisée Reclus

\section{Federico Ferretti}

\section{(2) OpenEdition}

Journals

\section{Edição electrónica}

URL: http://journals.openedition.org/espacoeconomia/513

DOI: 10.4000/espacoeconomia.513

ISSN: 2317-7837

Editora

Núcleo de Pesquisa Espaço \& Economia

\section{Refêrencia eletrónica}

Federico Ferretti, «"Eles têm o direito de expulsar-nos": a Nova Geografia Universal de Élisée Reclus », Espaço e Economia [Online], 3 | 2013, posto online no dia 19 dezembro 2013, consultado o 19 abril 2019. URL : http://journals.openedition.org/espacoeconomia/513; DOI : 10.4000/ espacoeconomia. 513

Este documento foi criado de forma automática no dia 19 Abril 2019.

(C) NUPEE 


\section{"Eles têm o direito de expulsar- nos": a Nova Geografia Universal de Élisée Reclus}

"Ils ont le droit de nous expulser" : La Nouvelle Géographie Universelle d'Élisée Reclus

"They have the right to throw us out": Élisée Reclus' New Universal

Geography

"Ellos tienen derecho de expulsarnos": La Nueva Geografía Universal de Élisée Reclus

Federico Ferretti

\section{NOTA DO EDITOR}

Artigo publicado inicialmente em inglês pela revista Antipode: a radical journal of geography, v.45, 2012, a quem agradecemos a autorização para a publicação em português. Esta tradução foi realizada por Guilherme Ribeiro e Lara D'Assunção dos Santos e faz parte das atividades do Laboratório Política, Epistemologia e História da Geografia (LAPEHGE/ UFRRJ), coordenado por aquele, e contou com auxílio da FAPERJ e da Fundação de Apoio à Pesquisa da UFRRJ.

\section{Introdução}

1 Em sua monumental Nouvelle Géographie Universelle (1876-1894), Élisée Reclus (1830-1905) tenta, como geógrafo ocidental, pela primeira vez, "provincianizar" a Europa no âmbito de uma dinâmica global. Aplicando suas idéias anarquistas à sua geografia, ele representa o princípio da unidade da espécie humana, declarando que todos os homens devem viver na Terra como "irmãos" e recusando a "superioridade" de uma cultura sobre as demais. 
Todavia, seu posicionamento acerca do estabelecimento de trabalhadores europeus no norte da África, que ele encarava com alguma simpatia, tem sido considerado por alguns geógrafos franceses como algo ambíguo. Alguns intelectuais, ao contrário, afirmam que muito desta visão é coerente com o pensamento anarquista e socialista da época, que considerava a emigração dos trabalhadores como uma forma de divulgar "idéias sociais" além-mar - desencorajando, assim, a dominação política ou militar. As novas pesquisas sobre Reclus são amplamente baseadas na exploração dos dezenove volumes da Nouvelle Géographie Universelle que, às vezes, tem sido considerada menos interessante que seus outros trabalhos - como L'Homme et la Terre que, atualmente, tem mostrado sua originalidade e seu papel no redimensionamento da Europa no pensamento geográfico.

Para evitar os perigos do anacronismo, é importante analisar o que Reclus disse no âmbito do contexto político e cultural de seu tempo. Quais foram as representações em torno da Europa, da Alteridade e do Colonialismo engendradas por um geógrafo muito influente e que, ao mesmo tempo, foi um dos fundadores do movimento anarquista internacional? Quais insights ele pode oferecer para os estudos contemporâneos sobre o colonialismo e pós-colonialismo? Tentaremos esclarecer tais questões destacando dois casos emblemáticos: o domínio britânico sobre a Índia e a ocupação francesa da Argélia tais como apresentados na Nouvelle Géographie Universelle.

Iniciaremos analisando a literatura existente quer sobre Reclus, quer sobre a relação entre a ciência européia e o colonialismo. Assim, consideraremos as representações de Reclus acerca do Império Britânico e, em seguida, do Império Francês. Finalmente, sintetizaremos sua construção em torno de uma nova crítica dos poderes coloniais incluindo as minorias. Nossa fonte primária é a Nouvelle Géographie Universelle, articulada a textos escritos para jornais políticos e à correspondência de Reclus.

\section{Reclus, Europa e Colonialismo}

4 Após a redescoberta de Reclus por acadêmicos francófonos e anglófonos durante os anos 1970 e 1980 (DUNBAR, 1978; Antipode, 1979; Hérodote, 1981), surgiu um debate entre alguns geógrafos franceses. Eles questionaram a simpatia manifestada, algumas vezes, por Reclus e seu grupo, a respeito do povoamento de terras como o Magreb por trabalhadores europeus - uma visão que, aparentemente, se chocava com sua ideologia política, já que Reclus era exilado da Comuna de Paris e, junto com Mikhail Bakunin, foi um dos fundadores do movimento anarquista internacional no âmbito da Associação Internacional dos Trabalhadores.

5 Alguns autores também têm levantado a hipótese de que Reclus era um "colonialista" (GIBLIN, 1981; NICOLAÏ, 1986; BAUDOIN \& GREEN, 2004). Em particular, o grupo da revista Hérodote * considerou suas posições "ambíguas" (GIBLIN, 1981:58) e, algumas vezes, inconsistente com seu pensamento anarquista, argumentando que, aparentemente, ele se mostrava menos crítico diante do colonialismo francês na Argélia do que em relação ao colonialismo britânico na Índia, por exemplo. Contudo, tais geógrafos analisaram apenas uma pequena parte do corpus documental reclusiano. Mais recentemente, após as conferências internacionais ocorridas em Lyon, Montpellier e Milão em 2005 por conta do centenário da morte de Reclus, outros pesquisadores (BORD et al., 2009; PELLETIER, 2009; SCHMIDT DI FRIEDBERG, 2007) iniciaram um trabalho sistemático ao redor de sua monumental produção geográfica - trinta mil páginas, sendo dezessete mil pertencentes 
à Nouvelle Géographie Universelle - e de sua correspondência profissional - mais de duas mil cartas publicadas e não-publicadas. Assim como alguns trabalhos clássicos da geografia francesa (por exemplo, BERDOULAY, 1981:70), esta nova investigação destaca os aspectos anti-coloniais da geografia reclusiana na expectativa de relativizar a definição de conceitos como Europa, Leste e Oeste; eles se apresentam como muito originais, sobretudo se os compararmos ao restante da ciência européia naquele período (DEPREST, 2005, 2012; FERRETTI, 2010; FERRETTI, MALBURET \& PELLETIER, 2011; GUARRASI, 2007; PELLETIER, 2007). As novas pesquisas revelam a intensa ligação entre a geografia reclusiana e o pensamento anarquista de então, guardando semelhança com alguns clássicos estudos anglófonos, que dialogavam com o anarquista Reclus, com o geógrafo Reclus ou com ambos sem apontar maiores contradições entre os dois (CLARK \& MARTIN, 2004; DUNBAR, 1978; FLEMING, 1988).

6 Novos estudos sobre Reclus noticiam um debate mais amplo na literatura francófona acerca das aberturas e dos limites das análises pós-coloniais, associadas a proeminentes teóricos do campo dos estudos subalternos (subaltern studies) e da crítica pós-colonial (por exemplo, BHABHA, 1994; CHAKRABARTY, 2000; MBEMBE, 2000; SPIVAK, 1999) que têm desfrutado de enorme sucesso em, provavelmente, cada domínio das ciências humanas particularmente entre geógrafos, historiadores, filósofos, antropólogos e sociólogos. Na França, acadêmicos como Jean-Loup Amselle e Jean-François Bayart têm criticado os estudos pós-coloniais, considerando-os anglocêntricos e, algumas vezes, muito generalistas ou essencialistas no emprego de categorias como "pensamento europeu" ou "ciência francesa" (AMSELLE, 2011; BAYART, 2010). Especialmente, Bayart defende a tradição intelectual francesa em relação à negligência diante do problema pós-colonial, explicando que muitos autores franceses contribuíram para questões anti-coloniais e referentes à descolonização muito antes da "virada pós-colonial" (BAYART, 2010:19-20). Se estes dois trabalhos contém, indubitavelmente, alguns elementos interessantes para o debate, eles estão claramente marcados por algum nacionalismo francês, que também negligencia a complexidade e a riqueza dos ambientes intelectuais pós-coloniais caracterizados, eles mesmos, pela pluralidade.

7 Por outro lado, outros franceses ou intelectuais francófonos como Nicolas Bancel e Catherine Coquery-Vidrovitch pregam "a marginalização da história colonial e a quaseausência da história pós-colonial na França até muito recentemente; esta é uma perda muito séria para a compreensão da crise vivida pela França atualmente" (COQUERYVIDROVITCH, 2011:47). Entretanto, artigos e livros inspirados pelo pensamento póscolonial floresceram na França nos últimos anos, ampliando a "biblioteca pós-colonial" francófona (COHEN, 2007).

8 De fato, os debates políticos sobre a memória e o significado da experiência colonial na França têm sido muito intenso nos últimos anos, ocupando-se, notadamente, do problema das heranças coloniais nos subúrbios franceses. Bancel define as recentes tendências que redescobriram alguns traços pretensamente "positivos" do colonialismo francês como um "turbilhão colonial” (BANCEL, 2011), destacando autores como Daniel Lefeuvre, Max Gallo e Pascal Bruckner. Atualmente, uma das questões que ocupa os autores inspirados pelo movimento pós-colonial é desafiar algo como uma "linha intelectual neoconservadora" (BANCEL \& BLANCARD, 2007:46).

9 Baseada em textos e arquivos originais, a mais recente pesquisa sobre a história da Geografia francesa está, geralmente, atenta a estes debates, buscando dialogar com os espaços pós-coloniais e tendo cuidado em distinguir a natureza diversa dos atores 
humanos e de problemas teóricos em diferentes épocas e lugares (SINGARAVÉLOU, 2009; Journal of Historical Geography, 2011). Além disso, em seu mais recente trabalho acerca da história das ciências francesas no período colonial, Pierre Singaravélou sublinha a importância da interlocução com a "produção do conhecimento em situação colonial", reconhecendo diferentes lugares, épocas e situações coloniais para identificar as feições de conformismo ou heterodoxia de cada autor. "A história destes lugares de produção nos permite situar e contextualizar o conhecimento geográfico colonial” (SINGARAVÉLOU, 2011:240).

10 Não temos espaço para sintetizar todos estes ricos debates mas, como hipótese de trabalho, podemos assumir (tal como fizemos em FERRETTI, 2011b) que a chave da distinção reclusiana entre conquista e colonização retoma, aproximadamente, à atual diferenciação entre colônias de povoamento e colônias de exploração, confundindo alguns autores mais familiarizados com a linguagem dos movimentos francófonos anticoloniais da segunda metade do século XX. De fato, Reclus usa a palavra colonização apenas no sentido das migrações ultramar dos trabalhadores europeus, expressando alguma simpatia por esse fenômeno como se pertencesse às idéias socialistas a serem exportadas para outros continentes. Em contraste, ele nega a legitimidade do vocábulo "colônias" quando aplicado a casos como a Índia britânica ou a Afrique Occidentale Française.

11 Citado frequentemente por pesquisadores reclusianos, o caso da Argélia Francesa merece ser esclarecido a partir de sua origem, e podemos fazê-lo através do corpus das cartas inéditas de Reclus para o cartógrafo francês Paul Pelet. Aqui, Reclus cedo expressa sua reflexão radicalizada sobre a colonização e sobre o princípio da conquista, desenvolvidas durante suas viagens iniciais à Argélia onde uma de suas filhas, Magali, residia com sua família. Em 1884, após sua experiência inicial com a situação argelina, ele renuncia à Société Protectrice des Indigènes, considerando-a muito paternalista e afirmando que "o que denominamos de proteção significa, às vezes, assistir ao trabalho da opressão" ${ }^{1}$. Por esta razão, ele diz: "Voltei para a Argélia horrorizado com a conquista (...) Quero, em absoluto, retirar meu nome da lista de pessoas que aceitam o princípio da conquista" ${ }^{2}$. Reprovando o comportamento de alguns amigos progressistas que permaneceram na associação, faz uma clara declaração anti-colonial: "Eu aprovaria este comportamento se os nativistas permitissem aos nativos todos os seus direitos, incluindo o de rejeitar-nos" ${ }^{3}$.

Se o texto da Nouvelle Géographie Universelle - publicado pela grande editora parisiense Hachette nos anos em que Reclus esteve exilado na Suíça - é mais prudente que suas correspondências inéditas, encontramos muitas passagens em que ele, algumas vezes implicitamente, condena os crimes coloniais. Além disso, comparado a outros escritos científicos e geográficos da época, podemos apontar alguns dos principais aspectos de sua originalidade científica. Por exemplo: se o ponto de partida da Nouvelle Géographie Universelle é a Europa, o que implica em alguma suspeita de eurocentrismo (conceito desconhecido no momento, todavia), é interessante comparar sua definição do Velho Continente com aquela dada pelo francófono geógrafo dinamarquês Conrad Malte-Brun que, em seu Précis de Géographie Universelle, escreve o seguinte:

"[A Europa é] a casa da humanidade e a legisladora do Universo. Ela está em todas as partes do mundo; um continente inteiro é povoado apenas por nossas colônias; barbaridades, desertos, sol e fogo não mais protegerão a África de nossos ativos empreendimentos. A Oceania parece clamar por nossos saberes e por nossas leis; a gigantesca massa asiática está quase que completamente atravessada por nossas conquistas. Logo a Índia Britânica e a Rússia Asiática tocarão uma a outra e o 
imenso, porém frágil, Império Chinês, não resistirá à nossa influência mesmo se escapar de nossos exércitos" (MALTE-BRUN, 1845:2). Bretanha era, simultaneamente, o berço da Revolução Industrial e um país cujas pequenas dimensões geográficas encontravam-se em evidente contraste com a enorme extensão de seu Império. da ciência, da tecnologia e da indústria, algo que aprendeu a observar durante suas frequentes viagens a Londres. Todavia, escrevendo no periódico socialista La Société Nouvelle, destacou, sem nenhuma ambiguidade, os equívocos do Império Britânico: "Sabemos qual foi o destino da Irlanda, assim como foi a conquista da Índia e o extermínio de australianos e maoris e, atualmente, o massacre dos matabelés; conhecemos os reformatórios e os cortiços de Whitechapel" (RECLUS, 1894:438). Entretanto, no dizer de Reclus, este gênero de dominação colonial trazia consigo os germes de sua futura derrota, pois os povos colonizados estavam aprendendo as ciências, as tecnologias e o pensamento crítico que permitiriam expulsar os invasores: "A civilização européia chegou a negar os seus pressupostos. Queria o poder e a dominação, mas construiu a igualdade por meio de suas próprias conquistas (RECLUS, 1894:438). 
18 Aqui, a palavra "igualdade" significa, principalmente, igualdade social. Naquela época, uma elaboração científica da teoria das diferenças culturais ainda não existia. Porém, Reclus sempre esteve atento para o que chamava "a boa vontade dos povos". No caso da Índia, tal princípio foi explicado em L'Homme et la Terre quando, a respeito da hipótese da independência do povo indiano, afirmou: "é importante que sua imaginação já esteja atenta ao sonho de uma 'Índia para hindus”' (RECLUS, 1908:52).

É muito raro encontrar declarações como esta em outros trabalhos científicos europeus de então. Em nossos dias, porém, os estudos subalternos concordam com o papel jogado pelo Império Britânico no estímulo indireto ao desenvolvimento de uma classe trabalhadora local na Índia. Se Dipesh Chakrabarty também criticou o marxismo como um ponto de vista europeu (CHAKRABARTY, 1989), precisamos considerar - tal como explicaremos a seguir - que o anarquismo é, no plano teórico, mais flexível que o marxismo, posto que não emprega o mesmo método dialético.

Além do mais, apoiado tanto por seu trabalho científico quanto por seu ativismo antiracista (ALAVOINE, 2007), o discurso reclusiano sobre as diferenças é amplamente baseado no conceito de miscigenação [mélange] e, aparentemente, muito similar ao princípio do "hibridismo" que, conforme Stuart Hall, é bastante utilizado nos estudos póscoloniais (HALL, 1996:259; ver também GILROY, 1993). O caminho de Reclus para que as "diferenças globais fizessem sentido" (KEARNS, 2005) também aparece em sua crítica aos atlas e mapas-múndi de então, onde ele antecipa alguns temas de autores como Arno Peters ou Brian Harley. Segundo Reclus, "mapas são mais falsos quanto maior for a porção da superfície terrestre representada; eles sempre iludem o leitor sobre a dimensão relativa de terras diferentes" (RECLUS, 1895:3-4).

21 A atitude radical expressa em La Société Nouvelle está presente em muitas páginas da Nouvelle Géographie Universelle. Por exemplo:

"Desafortunadamente, em muitos países os ingleses eram capazes somente de destruir, de consumir. Na Tasmânia, eles exterminaram os indígenas até o último homem. No continente australiano, algumas tribos nativas ainda escaparam deles como grupos de cangurus. Porém, este tipo de jogo humano está ameaçado de ser rapidamente extinto. Na Oceania, quantas ilhas foram despovoadas por eles e, em suas colônias americanas, agora Estados Unidos, quantas nações indígenas eles massacraram odiosamente - isto para não mencionar aquelas que eles assassinaram através do álcool e dos vícios europeus! (RECLUS, 1879:359). 
Fig.1: Superfície comparada do Hindustão e da Inglaterra

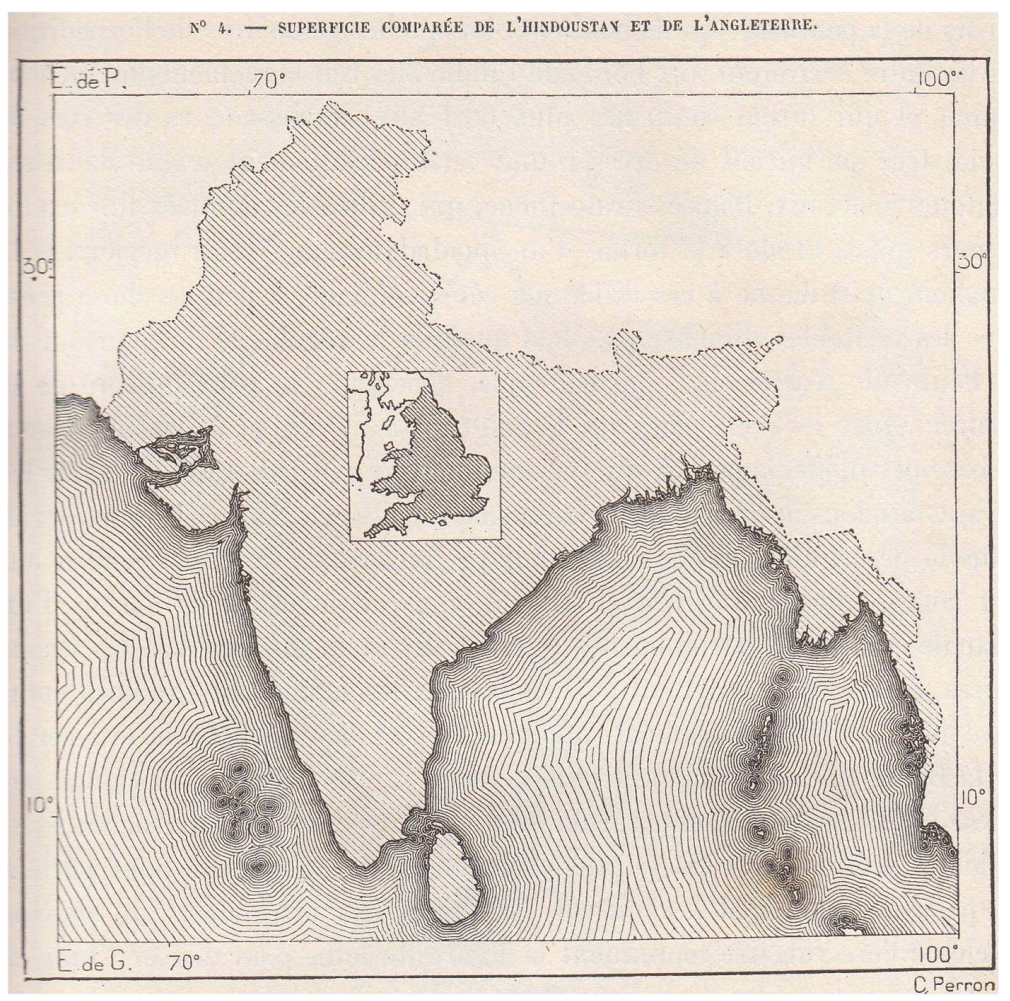

Fonte : RECLUS, 1883:21

Na Nouvelle Géographie Universelle, o choque entre as dimensões do país-mãe e as colônias é enfatizado com o emprego de mapas que hoje chamamos de "temáticos". Geralmente, eles se referem ao pequeno tamanho da Europa em comparação ao resto do globo por ela dominado. No caso britânico, a distinção entre colônias e conquistas está presente de forma muito clara. "Entre as possessões britânicas, alguns países como Canadá, Austrália e Nova Zelândia possuem uma existência verdadeiramente independente e desenvolvem-se por si mesmos com mais liberdade (...) Não é o caso da Índia: aqui, os ingleses não estão em casa, porque eles apenas a ocuparam com alguns milhares de dominadores" (RECLUS, 1894:434).

Reclus sublinha muitas vezes que esta distinção conceitual é substancial. Se o número de colonos europeus na Índia é demograficamente inconsistente, já que possuem apenas soldados e administradores, não podemos chamar tal país de colônia européia. "Com frequência, as pessoas denominam a Índia de 'colônia britânica' (...), mencionando-a como exemplo extraordinário de 'atitude colonializadora' dos anglo-saxãos. Todavia, a península cisgangética é o exemplo oposto" (RECLUS, 1883:629). Ele relata que havia mais fazendeiros brancos em Guadalupe do que em toda a Índia, e conclui argumentando que os colonos brancos daquela península consideravam-se a si mesmos como uma casta especial. Eles "não aceitariam que alguns de seus compatriotas comprometessem o prestígio de sua autoridade fazendo trabalhos manuais. A Índia é uma terra de conquista, e não uma colônia" (RECLUS, 1883:629).

Ademais, é preciso considerar que, nos ambientes anarquista e socialista de então, a noção de colônia pôde ser concebida independente de um estado ou de um aparato burocrático. Alguns grupos anarquistas tentaram fundar o que eles chamavam de 
“colônias sociais" em países tropicais. É o caso da Comuna Cecília, erguida no Brasil na última década do século XIX por um grupo de anarquistas italianos inspirados nas idéias de Reclus (ROSSI, 1993). Durante sua juventude, a fim de abrigar companheiros exilados pelo II Império, o próprio Reclus imaginou construir algo como uma colônia em Serra Nevada de Santa Marta, na Colômbia (RECLUS, 1861), seguindo a "utopia tropical" que, durante todo o século XIX, inspirara-se nas viagens de Humboldt (SAFIER, 2011). Nos anos seguintes, porém, ele tornou-se mais cético sobre tais possibilidades: em 1900, criticou a "moda" das colônias anarquistas, apontando que seus frequentes insucessos demonstravam a necessidade de agir na sociedade a fim de transformá-la. "Deviam os anarquistas criarem sua Icária fora do mundo burguês? Eu não penso assim e nem desejo isto" (RECLUS, 1900b:1). A idéia de colônias sociais tem notórios links com o saintsimonismo, que influenciou o jovem Reclus. Contudo, mais tarde ele tornou-se um incisivo crítico dos saint-simonianos, caracterizando-os como "homens poderosos no mundo da indústria" (RECLUS, 1885: 531) que empreenderam projetos como o Canal de Suez não mais por seus ideais, mas "em proveito de especuladores e financistas" (RECLUS, 1905: 323). Em geral, porém, é importante observar que, no século XIX, não era surpresa ouvir palavras como "colônias" ou "colonização" empregadas em acepções distintas das de nossos dias, e que uma certa defesa delas não era, a priori, uma contradição com os ideais anarquistas e socialistas daquela época.

25 A respeito da visão reclusiana sobre história e historicismo, recentemente Vincenzo Guarrasi tentou analisá-la inspirado no livro Provincializing Europe, de Chakrabarty (CHAKRABARTY, 2000). Como este último, Reclus destacou as contradições da Europa, que produziu a Declaração Universal dos Direitos do Homem e do Cidadão (1789) mas, sistematicamente, contradisse tal documento com sua própria atuação nos países colonizados. Se Reclus, que considerava a si próprio um homem inspirado pelo Iluminismo, foi influenciado pela tradição historicista criticada por Chakrabarty, contudo Guarrasi reconhece seu esforço "titânico" em compartilhar valores universais e, ainda assim, entender e relativizar diferenças culturais. De acordo com Guarrasi, a missão de Reclus foi "não deixar a história empurrá-lo para o canto. Compartilhando uma tradição intelectual e, ao mesmo tempo, contestando práticas políticas por ela inspiradas, foi um esforço titânico pelo qual ele devotou sua vida" (GUARRASI, 2007:94).

A noção reclusiana de humanidade é universal, algo que não está distante dos argumentos desenvolvidos por estudiosos que abordam a Revolução Haitiana (JAMES, 1938; BUCKMORSS, 2009), para quem a Declaração Universal foi um documento muito mais radical em seu potencial libertador do que as ações de seus autores europeus. Buck-Morss declara que a abolição da escravidão e a independência nacional no Haiti não foram dadas pela I República Francesa, mas, sim, tomadas pelos próprios escravos haitianos, "revelando a lógica da liberdade nas colônias (...); somente tal lógica legitimou sua revolução em termos universais - com os quais os franceses viam a si mesmos" (BUCK-MORSS, 2009:39-40).

Enfim, Reclus lida com a rivalidade entre o marítimo Império Britânico e o terrestre Império Russo na Ásia lançando mão de argumentos que parecem antecipar a "geopolítica" do célebre geógrafo britânico Halford Mackinder. De fato, ele percebia estes poderes coloniais como poderes globais que abarcavam o globo mas, a despeito de suas naturezas diferentes, logo se encontravam nas montanhas de Hindu Kush. Segundo Reclus, "o mundo oceânico inglês, estendido sobre toda a circunferência do planeta, constrasta com o mundo continental russo, que cobre metade da Europa e metade da 
Ásia" (RECLUS, 1889:713). Suas previsões na Nouvelle Géographie Universelle eram mais favoráveis à Rússia por uma razão geográfica: o Império Russo tinha uma verdadeira força demográfica e territorial na Ásia, enquanto o Império Britânico, disse ele profeticamente, estava destinado a deixar sua base de apoio na península indiana. "Em seu Império, o poder britânico não tem uma base de apoio natural: o crescimento normal da população hindu os conduzirá, por si próprios, à emancipação da tutela estrangeira" (RECLUS, 1879:885). Não é surpreendente que a teoria do heartland de Mackinder ${ }^{*}$ tenha sido parcialmente antecipada por Reclus, uma vez que sabemos das ligações diretas entre Mackinder e geógrafos anarquistas como Reclus e Kropotkin que, a despeito de suas visões políticas opostas, trocaram correspondências (KEARNS, 2004, 2009; FERRETTI, 2011a).

No que concerne ao domínio geopolítico, Gerry Kearns destaca as diferenças entre Mackinder e Reclus no tocante aos princípios do colonialismo afirmando que Reclus "rejeitou a força tão veementemente tanto quanto Mackinder abraçou-a, pois, para Reclus, isto rebaixava o agressor e degradava as vítimas produzindo, por sua vez, mais violência. Enquanto Mackinder apresentou uma visão do mundo dividido entre povos civilizados e povos bárbaros, argumentando que os britânicos eram excepcionais, Reclus enfatizou o entrelaçamento dos povos (...) Para ele, a diversidade cultural trouxe mais criatividade humana que a pureza racial" (KEARNS, 2009:187).

\section{O Império Francês}

Após a derrota na guerra contra a Prússia em 1870-1871, quando Reclus estava exilado na Suíça redigindo a Nouvelle Géographie Universelle, os debates na França sobre o usufruto da expansão colonial eram acalorados. Nas décadas anteriores, a França havia perdido territórios substanciais no Canadá, Louisiana e Índia e, em 1877, quando Reclus publicou o segundo volume da obra em questão - dedicado à França -, a maior parte do Império Francês era representado pela Argélia. As possessões do Senegal, Camboja e algumas ilhas no Pacífico e no Mar do Caribe não tinham muita relevância do ponto de vista políticoeconômico. Reclus estava claramente alinhado aos céticos, que reclamavam da "indiferença e da hostilidade do povo francês diante da colonização" (BERDOULAY, 1981:47).

De fato, em sua avaliação as colônias francesas eram um fenômeno residual:

“Tanto para a população quanto para o comércio, a totalidade das dominações estrangeiras contribuiu muito pouco para o crescimento da nação. (...) Colônias custam muito caro para as metrópoles, e suas populações, mantidas em condição de grande dependência, não podem colaborar para o desenvolvimento do fortalecimento francês. Assim, o poder da França não pode ser medido pela extensão das terras nas quais ela fincou sua bandeira" (RECLUS, 1877:913).

31 A respeito da Argélia, estudos recentes realizados por Florence Deprest afirmam que a idéia de explorar as possibilidades agrícolas no Norte da África por colonos europeus não era incoerente nem com o pensamento socialista - numa época em que conceitos como anti-colonialismo ou teoria do imperialismo eram desconhecidos -, nem com a noção reclusiana de unidade histórica e cultural da Bacia Mediterrânea (DEPREST, 2005, 2012). Aliás, no décimo primeiro volume da Nouvelle Géographie Universelle, dedicado ao Magreb, Reclus cita com frequência episódios de crimes coloniais ocorridos entre 1830 e a época em que vivia. Por exemplo, o massacre de uma tribo inteira aprisionada e sufocada em 
uma caverna onde, "de acordo com o testemunho de alguns sobreviventes, havia 1150 pessoas" (RECLUS, 1866: 502). Ele observava contínuos abusos promovidos por colonizadores e administradores: "muitas injustiças ainda estão sendo cometidas; os vencedores sempre abusam de sua força contra o povo mais fraco" (RECLUS, 1866: 630). Também condenava leis coloniais que permitiam a requisição das propriedades dos nativos, considerando-as "cruéis, bárbaras e inúteis" (RECLUS, 1866: 603).

Em suma, há amplas evidências reveladoras do anacronismo de alguns acadêmicos que afirmam que a geografia reclusiana contradizia seu anarquismo. De acordo com Deprest, um aspecto típico da originalidade de Reclus é a representação do nativo enquanto um indivíduo autônomo, com seu próprio direito à emancipação.

"Explicando como o regime colonial suplantou suas vozes, ele afirmava que povos nativos, árabes e berberes eram capazes de adquirir consciência política - o que significava que devíamos reconhecer que eles precisavam ter seus direitos políticos não em um vago futuro, mas naquele instante, além de percebermos que eles estavam sendo privados de seus direitos. Tais declarações abriram uma brecha nos princípios da dominação colonial, o que poderia acarretar o colapso de todo o edifício colonial" (DEPREST, 2012:120).

Em algumas das cartas de Reclus endereçadas a Paul Pelet, encontramos sua admiração por povos argelinos como os kabilas, chamados por ele de admiráveis cidadãos. "Estou completamente maravilhado pela mitologia kabila. Eu ficaria muito feliz de voltar aqui e estudar esses admiráveis cidadãos" ${ }^{4}$. Ele também ficou tocado por seus hábitos comunitários, que lhe fizeram recordar a democracia franca que admirava na pólis grega. Reclus concebia a assembléia aldeã dos kabila (djemâa) como um resquício de uma antiga tradição de liberdade oriunda da invasão arábica. "Espero que os kabila possam civilizar seus civilizadores" 5 .

Em suas correspondências, geralmente ele faz referência a um círculo de amigos locais nomeadamente, os anarquistas franceses colonos na Argélia - que gostavam de difundir idéias sociais entre a população local e se opunham a soldados, missionários e "protetores".

"Fiquei chocado com o julgamento unânime da Société Protectrice. Todo mundo a acusa de fazer o oposto do que diz; todo mundo enxerga nela a mão do Império; todo mundo a culpa de escolher os piores opressores como agentes locais. Todos eles têm três principais inimigos: o soldado, o padre e o 'protetor'! Meu Deus! Eu não estava em boa companhia!" ${ }^{6}$. 
Fig. 2: Uma das cartas inéditas de Reclus para Paul Pelet

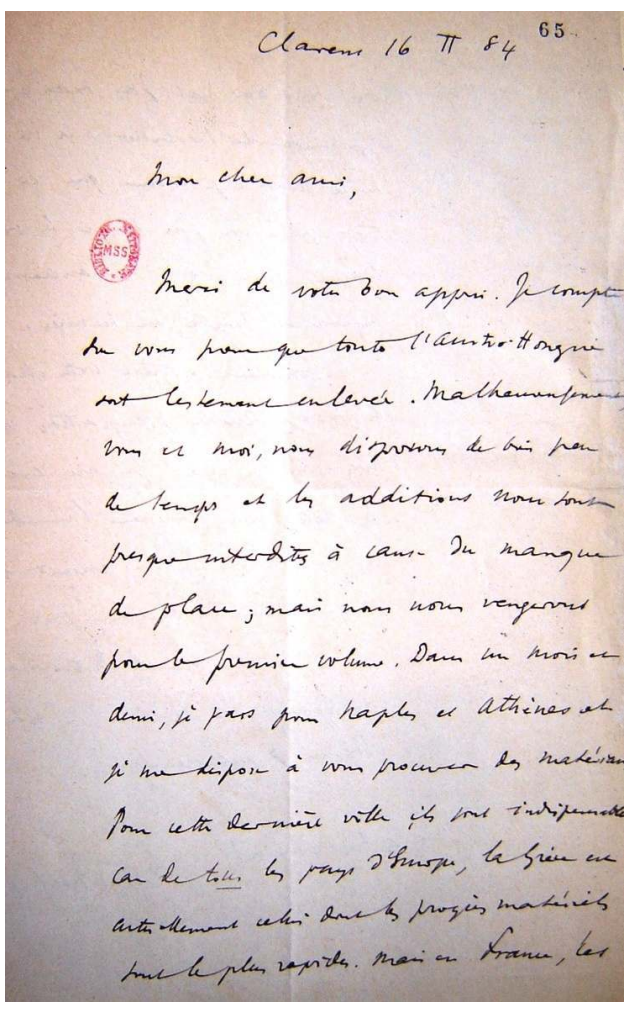

Fonte : BNF, NAF, 16798, f.65.

A partir de um outro conjunto de cartas inéditas que Reclus enviou ao anarquista genebrino Jacques Gross, podemos inferir que ele participou pessoalmente das tentativas de construir um movimento anarquista local na Argélia. "Quando deixei os argelinos ano passado, haviam dois ou três anarquistas. Agora, existem mais de cinquenta; a recente conferência [que eles organizaram] contou com quase quinhentas pessoas" ${ }^{7}$. Em uma de suas dedicatórias a Jules Perrier, outro communard francês exilado na Suíça, encontramos a expressão "volte para a Argélia, a terra dos espadachins [sabreurs]" (VUILLEUMER, 1972:13). A palavra sabreurs também pode ser traduzida como "assassinos" - em uma clara referência aos militares franceses situados no Norte da África responsáveis pela sangrenta repressão à Comuna de Paris.

Assim, em colônias estabelecidas como a da Argélia Reclus traça uma radical distinção entre trabalhadores europeus e exploradores europeus (patrões, administradores, missionários, soldados etc.). É importante esclarecer que, do ponto de vista anarquista, o problema social era sempre visto como mais importante (ou não menos importante) que $o$ colonial. De acordo com os anarquistas, um proletário argelino (ou de qualquer outro país) tinha, primeiramente, que lutar contra seu patrão. Ser francês, berbere ou árabe não era o problema principal. Alguns anos depois, em um artigo onde ilustra o caráter internacional da repressão, Reclus destacaria a necessidade de solidariedade entre proletários de diferentes países mencionando o massacre dos communards parisienses, executados por regimentos previamente estabelecidos na Argélia. Em Paris, "eles varreram subúrbios com suas artilharias tal como haviam destroçado os pobres brodji dos árabes. A França pagará o mesmo preço por Tonkin e Formosa. As recorrências históricas trarão punição pelas maldades cometidas" (RECLUS, 1911:339). 
37 Entretanto, os anarquistas da época também estavam atentos às lutas de libertação nacional, quer fossem na Europa ou nas colônias (ANDERSON, 2007). Conforme a perspectiva filosófica reclusiana inspirada em Pierre-Joseph Proudhon, a principal oposição era entre autoridade e liberdade. Como procedera em relação à Índia, Reclus concluiu seu discurso sobre a Argélia ressaltando o princípio da boa vontade dos povos. Um dia, os argelinos "se sentirão eles mesmos argelinos e não franceses e, necessariamente, oporão à metrópole um ideal de emancipação ou de uma federação livre" (RECLUS, 1905:427).

A respeito da África Sub-Saariana, é importante dizer que Reclus foi um dos primeiros autores a frisar a existência de uma original "civilização africana", que teve papel na formação do Antigo Egito e, logo, na fundação da civilização mediterrânea. Aqui, é preciso esclarecer que ele nega a existência de várias civilizações digladiando-se umas contra as outras, pois postulava uma única civilização humana, com diferentes características para cada povo ou região. Em sua visão, "o orgulho racial, do qual os historiadores não suspeitaram o suficiente, havia gerado e difundido muito preconceito, reivindicando que os africanos não tinham parte na obra geral da civilização [...] Ao contrário, a história de nosso progresso nos conduz, necessariamente, em direção à Bacia do Nilo, à terra africana" (RECLUS, 1885:32). Por outro lado, Reclus cita ironicamente a civilização européia (escrevendo a palavra entre aspas), condenando os prejuízos causados na África pelos traficantes brancos de escravos: "Foi a influência da civilização européia que piorou gravemente a condição do escravo africano" (RECLUS, 1885:41).

39 Nos anos em que Reclus escreveu os volumes da Nouvelle Géographie Universelle dedicados à África, os impérios europeus tinham, consoante o Congresso de Berlim de 1885, apenas começado a retalhar o vasto continente, onde ocuparam, efetivamente, pouco mais do que as regiões costeiras. Ele nota que "postos comerciais franceses não são numerosos" na Costa do Marfim, por exemplo (RECLUS, 1887:416). A respeito da Costa Negreira, embora quatro nações européias estivessem disputando entre si por influência regional, "no lado norte, na hinterlândia, suas propriedades ainda não tinham fronteiras delimitadas. Eram poucos os viajantes europeus que visitavam estes países" (RECLUS, 1887:462). Esta situação também diz respeito a um dos mais antigos portos marítimos dominado pela Europa: Senegal. "As possessões francesas de Senegâmbia ainda não têm outra cidade digna deste nome senão a capital" (RECLUS, 1887:248). As declarações reclusianas são confirmadas por historiadores contemporâneos como Jacques Frémeaux. Segundo ele, na zona conhecida à época como Sudão (correspondendo hoje ao Sahel), a administração francesa controlava um território militarmente limitado a "uma estreita faixa de terra de cada lado da estrada construída" (FRÉMEAUX, 1993:43).

Tratando das colônias francesas na África Ocidental, Reclus promove novamente uma distinção entre colônia e conquista indicando que, no Senegal

"este grupo de franceses não pode mesmo ser considerado como uma redução das sociedades européias, porque ele não é composto por todos os elementos orgânicos de uma nação, mas apenas por comerciantes e funcionários. Apesar do Senegal ser a mais antiga das 'colônias' francesas, é a mais impropriamente chamada de colônia (RECLUS, 1887:230).

41 Como muitos autores têm apontado, a Terceira República Francesa aplicou à África Ocidental o princípio da assim chamada valorização de seus recursos, o que supunha investir na construção de ferrovia e infraestrutura modernas (CONKLIN 1997; PUYO 2001; SURUN 2011). Reclus não se opõe a priori a este princípio; ele é mais favorável a este 
projeto do que à ferrovia Transsaariana. O que ele contesta é o princípio segundo o qual os benefícios destas obras sejam reservados aos conquistadores.

Por outro lado, ele encontra na África Ocidental o exemplo do que considera uma verdadeira colônia: o Estado da Libéria, a pátria dos escravos libertos - no momento em que autores europeus eram céticos sobre a capacidade de auto-governo dos povos negros.

"Não é um evento capital que a constituição de uma sociedade composta inteiramente por filhos de escravos ou de libertos tenha tomado por domínio um território onde os traficantes de escravos vinham formar seus grupos de prisioneiros? A despeito do que é dito, a Libéria está longe de ser um Estado mais frágil ou menos organizado do que as 'colônias' européias que a circundam. Ademais, sua vantagem reside em ser uma verdadeira colônia" (RECLUS, 1887:369).

Ele destaca a importância política desta experiência que, atualmente, poderia ser comparada, ironicamente, à "descolonização" em relação às grandes revoluções européias de 1848: "o grande ano das revoluções na Europa e na Ásia marcam o nascimento, em solo africano, da nova República Negra" (RECLUS 1887:370).

\section{Rumo a uma nova etnografia e a uma nova crítica ao colonialismo}

Em seus trabalhos geográficos, Reclus dedica espaço considerável aos povos nativos, às suas histórias, culturas e etnicidade, compartilhando tal interesse com seu irmão etnógrafo Elie Reclus (1827-1904), um dos principais colaboradores da Nouvelle Géographie Universelle. Irmão mais velho, ele também foi um dos primeiros autores a criticar as fontes com as quais, à época, os cientistas baseavam seu conhecimento nos assim chamados "selvagens". No início de seu livro Les Primitifs, ele anotou: "Não hesitamos em afirmar que em muitas tribos denominadas selvagens, a média individual não é nem moralmente, nem intelectualmente inferior aos indivíduos dos nossos denominados estados civilizados (...) Aquelas tribos estavam sendo descritas apenas por seus invasores, que poderiam, pelo menos, compreendê-los" (ELIE RECLUS, 1885: XIII-XVI).

Naquele tempo, boa parte destes povos morava na zona tropical. De acordo com Pierre Singaravélou, geógrafos europeus viam nos trópicos “a perfeita expressão de suas análises esquemáticas baseadas na influência do meio sobre o homem" (SINGARAVÉLOU, 2009:49). Enquanto os irmãos Reclus não eram exceções a este olhar, o enfoque deles residia nas diferentes estratégias de adaptação desenvolvida por cada povo. Este discurso foi muito útil para suas políticas igualitárias porque, em sua visão, a relativização das condições materiais tornou possível apreciar a inteligência e a habilidade dos povos em relação ao ambiente, sem nenhuma razão que justificasse falar em 'superioridade' ou 'inferioridade' de uma cultura. Naturalmente, Elisée Reclus é irônico a respeito de certos chavões ao redor dos habitantes dos trópicos. No volume da Nouvelle Géographie Universelle dedicado à África Ocidental, ele argumenta que "o povo krous contradiz fortemente a idéia preconceituosa de que o homem das terras tropicais é incuravelmente preguiçoso; eles trabalham com energia e perseverança e são muito vigorosos" (RECLUS, 1887:387).

Reclus também argumenta acerca dos arranjos políticos de diferentes tribos e grupos étnicos nos trópicos. Ele analisa a organização tribal da região Bambouk empregando uma terminologia que remete aos debates políticos contemporâneos na Europa. "A região Bambouk é a parte da bacia do Senegal onde as aldeias, quase todas habitadas pelos Pagan Mandingos, preservam melhor sua independência republicana e sua organização 
federativa" (RECLUS, 1887:264). A idéia de "republicanismo" aparece muitas vezes neste volume da Nouvelle Géographie Universelle, tal como quando o autor refere-se às "comunidades republicanas" (RECLUS, 1887:469) dos Minas na Costa Negreira. Isso revela que a visão reclusiana não admitia os povos africanos como objetos, mas enquanto cidadãos com os mesmos direitos dos europeus. No ambiente colonialista francês de então, era raro e difícil ouvir alguém chamar os nativos de republicanos pois, em francês, a expressão implica em plenos direitos de cidadania e total compromisso com a história e a tradição da nação após a Revolução de 1789. Reclus também está interessado nas diferenças de classe no interior das sociedades africanas. Observando Ashanti (estado de Gana), ele nota que "a separação e os privilégios classistas de povos poderosos são mais importantes e respeitadas aqui do que em todos os outros países" (RECLUS, 1887:430).

Por fim, Reclus, que passara boa parte de sua juventude defendendo os abolicionistas durante a Guerra de Secessão Americana (ALAVOINE-MULLER, 2007), exalta a dignidade do povo negro, que resistiu o máximo possível à escravidão do outro lado do Atlântico. Os denominados Minas "foram os que lutaram com mais frequência para recuperar sua liberdade e, no interior do Brasil, constituíram a mais próspera e a mais bem protegida comunidade de fugitivos" (RECLUS, 1887:470).

Em 1889, ao terminar de compilar a Nouvelle Géographie Universelle, Reclus iniciou outras séries de trabalhos notáveis sobre a questão colonial como um todo, começando com resenhas publicadas no periódico Humanité Nouvelle (novo nome da antiga Société Nouvelle ). Resenhando Jours de Guinée de Pierre d'Espagnat, Reclus declarou-se indignado com a sociedade colonial e desejou viver em um país onde

“as atrocidades contra os povos negros não fizessem parte das boas maneiras. Tais páginas ensinam-nos bastante sobre a 'civilização' que nossos compatriotas trouxeram ao continente africano. Elas descrevem pequenos prisioneiros de sete ou oito anos de idade, cujos pais tiveram a garganta cortada, trazidos para aldeias negreiras para serem vendidos a algum rei negro de um pequeno país ou a algum mercador europeu, que completará sua educação com seu porrete" (RECLUS, 1899a).

Em sua resenha de La colonia Eritrea, do italiano Meldi, Reclus é irônico ao relatar o grotesco esforço colonial da Itália sob Francesco Crispi. "Nós não precisamos dizer que, de acordo com o autor, cheio de fé patriótica, os italianos têm todos os direitos nesta empreitada, tanto contra os nativos como contra seus concorrentes europeus" (RECLUS, 1900a).

Um livro sobre as colônias francesas na Indochina é uma oportunidade para divulgar que a escravidão existe mesmo sob direta administração francesa. Reclus irrita-se com os

"homens de negócio e especuladores famintos por ouro que vivem no país para explorar completamente os vinte milhões de annameses e tonkineses (...) Sob a administração do republicano radical Doumier, o comércio de escravos annameses foi instituído em benefício de alguns aproveitadores recomendados por banqueiros parisienses. Para comprar um homem, basta fazê-lo assinar um papel em francês" (RECLUS, 1899c).

Portanto, exportar a civilização francesa significa tornar alguém escravo por meio da assinatura de papéis — na linguagem da Declaração de 1789!

Todavia, o livro que mais irritou Reclus foi uma obra declaradamente racista: Psychologie de la colonisation française, de Léopold de Saussure. "Os fanáticos do império colonial podem encontrar inúmeros exemplos das falhas cometidas na 'educação de nossos irmãos inferiores"' (RECLUS, 1899b:247). Aqui, o tom irônico dá lugar à denúncia contra todos os 
europeus que partem rumo ao estrangeiro e sentem-se infinitamente superior aos nativos. Para Reclus, não é nenhuma surpresa que a mesquinha instrução européia recebida aguce o espírito de rebelião local:

"Como poderia ser diferente? Esse ódio do escravo que se revolta contra nós é correto e prova, pelo menos, que ainda há esperança de emancipação. É natural que hindus, egípcios, kaffirs e irlandeses odeiem os ingleses; é natural que os árabes execrem os europeus. Isso é justiça!" (RECLUS, 1899b:247).

53 Em seu último trabalho, L'Homme et la Terre (1905-1908), Reclus transfere esse gênero de análise para o contexto dos impérios coloniais. Em uma passagem a respeito da colonização africana, encontramos uma precoce ocorrência do termo "imperialismo", bem como um claro repúdio às teses da direta influência climática sobre o comportamento dos indivíduos:

"Concernente aos crimes cometidos em muitas circunstâncias pelos exércitos coloniais, que despertaram o sentimento universal de indignação, alguns teorizaram que a influência do sol tropical pode ser a causa de uma doença especial chamada 'sudanite', que afeta, especialmente, os oficiais superiores, fazendo com que eles comentam crimes sem nenhuma razão aparente. A invenção desta doença por oficiais superiores, que possui a grande vantagem de fazer com que eles não sejam culpados pelos tribunais militares, assemelha-se à brilhante idéia criada para justificar o roubo de lojas quando cometido por ricas damas que, absolutamente, não precisam do que roubaram. Trata-se de um simples caso de cleptomania, referente à medicina e não aos tribunais. Contudo, sobre os oficiais deixarem uma imensa dominação colonial, suas loucuras criminais podem ser facilmente explicadas sem o 'sudanite': é puro poder, exercido sobre pessoas consideradas algo menos que gente e sem o risco de semelhante julgamento. Este poder logo se tornará um estilo romano de imperialismo ou simples perversidade (RECLUS, 1908: 206-208)

Tanto na Nouvelle Géographie Universelle quanto em L'Homme et la Terre, Reclus não abre exceções para o menor dos poderes imperiais. No que tange à América, ele escreve que em cada canto deste continente, dos Vikings no século XI aos Conquistadores no século XVI, "o massacre começou com a chegada do povo branco" (RECLUS, 1890:13). A Holanda é definida simplesmente como a "parasita de Java" (RECLUS, 1879:336) o reino da Bélgica é severamente censurado por seus crimes no Congo, caracterizados como parte do comércio geral europeu:

“entre todos os crimes cometidos na África pelos brancos, os praticados no 'Estado Independente do Congo' talvez sejam os piores. São os mais recentes e os mais organizados cientificamente. Porém, quem são ingleses, alemães e franceses para, com mãos suficientemente limpas, protestarem sem suspeita de parcialidade?" (RECLUS, 1905:447).

\section{Conclusão}

Nos anos 80, alguns autores (ver Hérodote, 1981) afirmaram que, entre os escritos geográficos de Reclus, o mais radical e "interessante" seria o último, L'Homme et la Terre, com a Nouvelle Géographie Universelle sendo considerado um trabalho mais convencional. Agora, novas pesquisas ao redor deste gigantesco corpus têm mostrado que, embora a Nouvelle Géographie Universelle nunca tenha sido planejada para ser um instrumento de propaganda, ela ocupa um lugar importante na construção de um discurso crítico sobre Europa, Alteridade e Colonialismo. 

primazia da Europa nos trabalhos geográficos (menos de um terço dela é dedicada à Europa), além de ter ensaiado representar todos os povos do globo de acordo com os princípios da unidade humana e fraternidade (RECLUS, 1876:IV). Ao fazê-lo, ele encorajou leitores a situarem a si mesmos em uma posição relativa para a compreensão do Outro, sem julgamentos de superioridade ou inferioridade. Ele declarava que a progressiva globalização - palavra que não existia à época, mas cujo conceito já estava claro - faria com que a Europa e a Alteridade se aproximassem cada vez mais tanto do ponto de vista material quanto cultural. No dizer de intelectuais pós-coloniais contemporâneos, "Todo lugar é constitutivo do Aqui e vice-versa; não há mais Dentro e Fora" (BANCEL et al., 2010:21). Segundo Reclus, o mundo é um globo "cujo centro está em todo lugar e a circunferência em lugar nenhum" (RECLUS, 1876:7).

Em terceiro, as condenações reclusianas sobre os crimes coloniais são fortes e frequentes em sua obra geográfica. Elas antecipam a crítica ao colonialismo e ao imperialismo que o movimento socialista europeu adotaria nas primeiras décadas do século XX e que, ainda hoje, permanecem um problema aberto. Além disso, seu trabalho pode ser uma estimulante contribuição para os atuais estudos subalternos e pós-coloniais, especialmente em sua dimensão geográfica. De fato, autores pós-coloniais, começando pelo trabalho pioneiro de Edward Said (SAID, 1978), construíram ferramentas intelectuais frequentemente citadas em recentes livros de história do pensamento geográfico. Sua coerência para com as questões pós-modernas e a pluralidade de visões possibilitadas por um "pós" que significa "não apenas 'depois', mas 'indo além”" (STUART HALL, 1996:53) faz do pensamento colonial algo muito atraente para a pesquisa geográfica. Atualmente, ela está envolvida com típicas noções pós-coloniais, tais como marginalização ou alteridade (SPIVAK, 1985). Reclus é um exemplo de uma via diferente de lidar com a Alteridade. De qualquer modo, ele pertence à tradição européia e era um produto de seu tempo. Porém, sempre tentou entender o ponto de vista de todos os povos, localizando a si próprio como um deles ao invés de julgá-los; assim, desenvolveu um discurso científico que se apresentou como muito heterodoxo para o seu tempo. Sua atenção às diferenças culturais está sempre articulada à sua análise da dominação. Tal como Gerry Kearns argumentou: "A subjugação abusou do povo subjugado (...) Sinais tidos pelos orientalistas como marcas de decadência eram, para Reclus, evidências de má administração" (KEARNS, 2009:187).

Como dissemos, Reclus estava desconfortável com Hegel, cuja Fenomenologia agora é considerada um "texto fundador do poderio colonial europeu" (GIDWANI, 2008:2583). Não foi por acaso que, no século seguinte, Frantz Fanon conseguiu lidar com o "momento subalterno" da dialética hegeliana apenas quando inverteu criativamente seu legado por meio de uma "fidelidade insurrecionária" (GIDWANI, 2008:2585). Reclus, Kropotkin e outros anarquistas da época criticaram tanto a dialética hegeliana quanto a marxista como um método igualmente metafísico, mesmo se aplicado ao materialismo (KROPOTKIN, 1908). Suas principais referências filosóficas eram a Encyclopédie, a Naturphilosophie e a dialética "binária" ou "serial" de Proudhon (PELLETIER, 2009) que também inspiraram, junto com Bakunin, suas perspectivas federalistas. Segundo 
Kropotkin, o anarquismo dialogou com as ciências sociais aplicando um método preferencialmente empírico e pragmático, que nos remete à fenomenologia contemporânea e às abordagens sistêmicas. Conforme Claude Raffestin, este método faz da geografia reclusiana algo muito engajado com a complexidade e com as diferenças: "Reclus nunca se fechou dentro de uma teoria rígida onde a Geografia seria 'isto e não aquilo'; em sua vontade de mostrar e de explicar, ele preferiu dizer 'isto e aquilo' (RAFFESTIN, 2008:165). Encontramos afirmação semelhante na clássica biografia redigida por Max Nettlau, que comparou o método geográfico da Nouvelle Géographie Universelle e as abordagens anarquistas anti-dogmática e anti-metafísica recuperando as epistemologias críticas de Karl Popper e Paul Feyerabend. De acordo com Nettlau, "apenas um anarquista poderia terminar esta obra onde milhões de particularidades aparecem em uma ordem harmônica, porque ele tinha o espírito amplo e flexível o suficiente para conferir, a cada problema, seu lugar - sem forçá-lo a adentrar em um sistema teórico pré-concebido" (NETTLAU, 1930:30).

Além disso, nas noções reclusianas de migração e miscigenação como os mais importantes fatores de impulsão da história mundial, encontramos a antecipação da idéia contemporânea de um complexo sistema mundial - algo bastante próximo das afirmações de Eric Wolf em sua obra clássica sobre povos sem história, quando sublinha a natureza interconectada da história humana e argumenta que "a busca por um mundo de pureza é ilusória" (WOLF, 1982:17).

Inevitavelmente, decerto que Reclus compartilhava os limites de um pensador europeu do século XIX, e seus prognósticos sobre o progresso social e a "fraternidade universal" são certamente muito otimistas se considerarmos a história do século XX. Porém, este gênero de universalismo não é a afirmação de uma assimilação necessária ou de um processo evolutivo fixo, mas, antes, uma declaração de sua esperança na expansão mundial dos princípios de "cooperação" e "livre federação". Encontramos declarações do mesmo gênero "universalístico" no atual debate pós-colonial, notadamente quando Achille Mbembe - com uma linguagem que nos parece muito próxima da de Reclus - assevera que "o pensamento pós-colonial sublinha a humanidade-em-formação, a humanidade que emergirá quando as figuras coloniais da barbaridade e das diferenças raciais tiverem sido eliminadas pelo advento de uma comunidade fraternal universal" (MBEMBE, 2008). Assim, universalismos críticos são possíveis, e podemos compreendê-los melhor no momento em que pensadores críticos como Reclus ainda puderem dar sua contribuição aos estudos pós-coloniais e subalternos.

Finalmente, podemos sustentar que Elisée Reclus, seu irmão Elie e alguns outros colaboradores da Nouvelle Géographie Universelle - como os geógrafos anarquistas russos Kropotkin e Mechnikov (FERRETTI, 2011a) - demonstraram a existência de pensadores heterodoxos na ciência européia do século XIX que não estavam alinhados aos discursos colonialista e racista dominantes. Evitando o anacronismo, é importante estudar suas obras para preservar e considerar criticamente os traços de uma outra perspectiva européia de ver o mundo. 


\section{BIBLIOGRAFIA}

Arquivos

Paris - Bibliothèque Nationale de France (BNF), Nouvelles Acquisitions Françaises, 16798, letras de Élisée Reclus a Paul Pelet.

Lausanne - Centre international de Recherches sur l'Anarchisme (CIRA), Jacques Gross Papers.

Fontes impressas

[Anônimo] (1875) Variétés. Bulletin de la Fédération Jurassienne, 13 June:4.

Dubois M. (1892) Rôle des articulations littorales : étude de géographie comparée. Annales de Géographie, 1 :131-142.

Kropotkin P (1908) Modern science and anarchism. New York: Mother Earth Publishing Association.

Malte Brun C (1845) Précis de la Géographie Universelle, tome deuxième, description de l'Europe. Paris: $\mathrm{Au}$ Bureau des publications illustrées (5me éd.).

Reclus Elie (1885) Les primitifs. Paris, Chamerot.

Reclus Élisée (1861) Voyage à la Sierra Nevada de Sainte-Marthe : paysages de la nature tropicale. Paris, Hachette.

Reclus Élisée (1876) Nouvelle Géographie Universelle, vol. I, Europe Méridionale. Paris: Hachette.

Reclus Élisée (1877) Nouvelle Géographie Universelle, vol. II, La France. Paris: Hachette.

Reclus Élisée (1879) Nouvelle Géographie Universelle, vol. IV, Europe du Nord-Ouest. Paris: Hachette.

Reclus Élisée (1883) Nouvelle Géographie Universelle, vol. VIII, Inde et Indochine. Paris: Hachette.

Reclus Élisée (1885) Nouvelle Géographie Universelle, vol. X, L'Afrique Septentrionale : Bassin du Nil, Soudan Égyptien, Éthiopie, Nubie, Égypte. Paris: Hachette.

Reclus Élisée (1886) Nouvelle Géographie Universelle, vol. XI, L'Afrique Septentrionale : Tripolitaine, Tunisie, Algérie, Maroc, Sahara. Paris: Hachette.

Reclus Élisée (1887) Nouvelle Géographie Universelle, vol. XII, L'Afrique Occidentale, Archipels atlantiques, Sénégambie et Soudan Occidental. Paris: Hachette.

Reclus Élisée (1889) Nouvelle Géographie Universelle, vol. XIV, Océan et terres océaniques. Paris: Hachette.

Reclus Élisée (1890) Nouvelle Géographie Universelle, vol. XV, Amérique Boréale. Paris: Hachette.

Reclus Élisée (1894) Hégémonie de l'Europe. La Société Nouvelle, 112:433-443.

Reclus Élisée (1899a) Pierre d'Espagnat, Jours de Guinée, Paris, Perrin, 1899. L'Humanité Nouvelle, 23:626.

Reclus Élisée (1899b) Léopold de Saussurre, Psychologie de la colonisation française dans ses rapports avec les sociétés indigènes, Paris, Alcan, 1899. L'Humanité Nouvelle, 26:246-248.

Reclus Élisée (1899c) J. de Saint-Maurice Joleaud-Barral, La colonisation française en Annam et au Tonkin, Paris, Plon, 1899. L'Humanité Nouvelle, 28:10. 
Reclus Élisée (1900a) R. Meldi, La colonia Eritrea, Parma, Battei, 1899. L'Humanité Nouvelle, 35:620.

Reclus Élisée (1900b) Les colonies anarchistes. Les Temps Nouveaux. 7-13 juillet :1-2.

Reclus Élisée (1905) L’Homme et la Terre, vol. V, Paris: Librairie Universelle.

Reclus Élisée (1908) L'Homme et la Terre, vol. VI, Paris: Librairie Universelle.

Reclus Élisée (1911) Correspondance, vol. I, Paris: Schleicher Frères.

Referências Bibliográficas

Alavoine-Muller S (2007) Introduction. In Reclus É Les États-Unis et la Guerre de Sécession: articles publiés dans la Revue des Deux Mondes, Paris: CTHS.

Anderson B (2007) Under three flags: anarchism and the anti-colonial imagination. London: Verso.

Antipode, a Radical Journal of Geography - Special Issue Geography and Anarchism, 10-11 (1979).

Amselle J-L (2011) L'Occident décroché, enquête sur les postcolonialismes. Paris: Fayard/Pluriel (2 $2^{\text {nd }}$ edition).

Bancel N, Blanchard P (2007) La fracture coloniale : retour sur une réaction. Mouvements, 51: 40-51

Bancel N, Bernault F, Blanchard P, Boubeker A, Mbembe A, Vergès F (2010) Ruptures postcoloniales : les nouveaux visages de la société française. Paris: La Découverte.

Bancel N (2011) Le maelström colonial : politique de la mémoire coloniale et rôle de l'histoire universitaire. Canadian Journal of African Studies/Revue Canadienne d'Études Africaines, 45:45-76.

Baudouin A, Green H (2004) Reclus, a colonialist? Cybergeo, revue européenne de géographie : http:// www.cybergeo.eu/index4004.html.

Bayart J-F (2010) Les études postcoloniales, un carnaval académique. Paris: Karthala.

Berdoulay V (1981) La formation de l'école française de géographie. Paris: CTHS.

Bhabha H (1994) The location of culture. London: Routledge.

Bord J-P, Cattedra R, Creagh R, Miossec J-M, Roques G, eds. (2009) Élisée Reclus, Paul Vidal de la Blache, la géographie, la cité et le monde, hier et aujourd'hui, autour de 1905. Paris:

L'Harmattan.

Buck-Morss S (2009), Hegel, Haiti and universal history. Pittsburgh, University of Pittsburgh Press.

Chakrabarty D (1989) Rethinking Working-Class History: Bengal 1890 to 1940. Princeton: Princeton University Press.

Chakrabarty D (2000) Provincializing Europe, postcolonial thought and historical difference. Princeton/ Oxford: Princeton University Press.

Clark J-P Martin C, eds. (2004) Anarchy, geography, modernity: the radical social thought of Élisée Reclus , Lanham (Md.): Lexington Books.

Cohen J (2007) La bibliothèque postcoloniale en pleine expansion. Mouvements, 51: 166-170.

Colloque international Élisée Reclus et nos géographies. Textes et prétextes, Lyon 2005 (CD-Rom). Conklin A (1997) A mission to civilize: the republican idea of Empire in France and West Africa, 1895-1930. Stanford: Stanford University Press.

Coquery-Vidrovitch C (2011) Colonisation, racisme et roman national en France. Canadian Journal of African Studies/Revue Canadienne d'Études Africaines, 45:17-44. 
Deprest F (2005) Reclus et la colonisation de l'Algérie. Colloque international "Élisée Reclus et nos géographies. Textes et prétextes", Lyon (CD-Rom).

Deprest F (2012) Élisée Reclus et l'Algérie colonisée. Paris: Belin.

Dunbar G (1978) Élisée Reclus historian of nature. Hamden: Archon Books.

Ferretti F (2010) L'egemonia dell'Europa nella Nouvelle Géographie Universelle (1876-1894) di Élisée Reclus: una geografia anticoloniale? Rivista Geografica Italiana, 117:65-92http:// halshs.archives-ouvertes.fr/halshs-00487181/fr/

Ferretti F (2011a) The correspondence between Élisée Reclus and Pëtr Kropotkin as a source for the history of geography. Journal of Historical Geography, 37:216-222.

Ferretti F (2011b) L'Occident d'Élisée Reclus, l'invention de l'Europe dans la Nouvelle Géographie Universelle (1876-1894). PhD dissertation defended on February 14, 2011. Universities of Bologna and Paris 1; Supervisors: F. Farinelli and M.-C. Robic.

Ferretti F, Malburet Ph, Pelletier Ph (2011) Élisée Reclus et les Juifs : étude géographique d'un peuple sans État. Cybergeo, revue européenne de géographie: http://cybergeo.revues.org/ index23467.html

Fleming M (1988), The geography of freedom: the odyssey of Élisée Reclus. Montreal: Black Rose Books. Frémeux J (1993) L'Afrique à l'ombre des épées, 1830-1930, vol. I. Paris: SHAT.

Giblin B (1981) Élisée Reclus et les colonisations. Hérodote, 22: 56-79.

Gidwani V (2008) The subaltern moment in Hegel's dialectic. Environment and Planning A, 40: 2578-2587.

Gilroy P (1993) Black Atlantic: modernity and double consciousness. Cambridge: Harvard University Press.

Guarrasi V (2007) All'ombra delle culture. In: Schmidt di Friedberg M. (ed.), Élisée Reclus: Natura e Educazione. Milan: Bruno Mondadori.

Hall S (1996) When was the postcolonial? Thinking at the limit. In Chambers I, Curtis L (eds.) The post-colonial question, common skies, divided horizons. London: Routledge: 213-220.

Hérodote, Élisée Reclus, un géographe libertaire, n. 22 (1981)

James C R L (1938) The Black Jacobins, Toussaint L'Ouverture and the San Domingo Revolution. London: Secker \& Warburg.

Journal of Historical Geography, Feature: French Geography, Cartography and Colonialism, 37, 2 (2011)

Kearns G (2004) The political pivot of geography. The Geographical Journal, 170: 337-346.

Kearns G (2005), Making sense of global differences. Colloque international “Élisée Reclus et nos géographies. Textes et prétextes", Lyon (CD-Rom).

Kearns G (2009) Geopolitics and Empire: the legacy of Halford Mackinder. Oxford: Oxford University Press.

Mbembe A (2000) On the Postcolony. University of California Press.

Mbembe A (2008) What is the postcolonial thinking ? Eurozine, http://www.eurozine.com/ articles/2008-01-09-mbembe-en.htm

Nettlau M (1930) Eliseo Reclus: vida de un sabio justo y rebelde, vol. II. Barcelona: Edicciones de la Revista Blanca. 
Nicolaï H (1986) Élisée Reclus et l'Afrique. Revue Belge de Géographie, 34:95-108.

Pelletier Ph. (2007) La grande séparation à résorber: l'Orient et l'Occident vus par Élisée Reclus, Raforum: http://raforum.info/reclus/spip.php?article21.

Pelletier Ph (2009) Élisée Reclus, géographie et anarchie. Paris: Éditions du monde libertaire.

Puyo J-Y (2001) Sur le mythe colonial de l'inépuisabilité des ressources forestières (Afrique occidentale française/Afrique équatoriale française, 1900-1940). Cahiers de géographie du Québec, 126: $479-496$

Raffestin C (2008) Commento. In Reclus E Storia di una montagna. Verbania: Tararà Edizioni. Rossi G (1993) Cecilia colonia anarchica sperimentale. Un episodio d'amore nella colonia "Cecilia". Pisa: Bfs.

Said E (1978) Orientalism. New York: Vintage Books.

Safier N (2011) Transformations de la zone torride : les répertoires de la nature tropicale à l'époque des Lumières. Annales Histoire Sciences Sociales, 66:143-172.

Schmidt di Friedberg M., ed. (2007) Élisée Reclus: natura ed educazione. Milan: Bruno Mondadori. Singaravélou P, ed. (2009) L'empire des géographes, géographie, explorations et colonisation, $19^{e}-20^{e}$ siècle. Paris: Belin.

Singaravélou P (2011) Professer l'Empire, les « sciences coloniales en France sous la IIIe République. Paris: Publications de la Sorbonne.

Spivak Gayatri C (1985) Three women's text and critique of Imperialism. Critical Inquiry 1-2, no.12: 242- 261.

Spivak Gayatri C (1999) Critique of postcolonial reason. Cambridge/London: Harvard University Press.

Surun I (2011) French military officers and the mapping of West Africa: the case of Captain Brosselard-Faidherbe. Journal of Historical Geography, 37: 167-177.

Vuilleumier M (1972) Élisée Reclus et Genève. Musées de Genève, 114 :9-13.

Wolf E (1982) Europe and the people without history. Berkeley/Los Angeles/London: University of California Press.

\section{NOTAS}

*. Hérodote é a revista de geografia e de geopolítica fundada por Yves Lacoste em janeiro de 1976. Publicada até hoje, ela teve papel importante nos debates que animaram a esquerda francesa na conjuntura da Guerra Fria. A maior parte de seus volumes está disponível on-line no site da Bibliothèque Nationale de France (BNF). Para maiores informações sobre o impacto da Hérodote, consulte: CLAVAL, Paul. Hérodote and the French Left. In: ATKINSON, David, DODDS, Klaus (ed.). Geopolitical Traditions: Critical Histories of a Century of Geopolitical Thought. London, Routledge, pp. 239-267 (2000). (N.T.).

1. Bibliothèque Nationale de France, Nouvelles Acquisitions Françaises (daqui em diante, BNF, NAF), 16798, f. 74, Lettre d'É. Reclus à P. Pelet, 28 mai 1884.

2. BNF, NAF, 16798, f. 77, Lettre d'É. Reclus à P. Pelet, 21 juin1884.

3. BNF, NAF, 16798, f. 80, Lettre d'É. Reclus à P. Pelet, 7 décembre 1884. 
* Vale lembrar que Marcel Dubois (1856-1916) foi o primeiro ocupante da recém-criada cadeira de Geografia Colonial na Sorbonne em 1892. No ano anterior, ele fundara os Annales de Géographie ao lado de Paul Vidal de la Blache (N.T.).

* A esse respeito, vide o clássico texto o pivô geográfico da história, de John Halford Mackinder, recentemente traduzido para o português por Fabrício Vasselai e disponível on-line na revista Geousp - espaço e tempo, n.29, 2011 (N.T.).

4. BNF, NAF, 16798, f.74, Lettre d'É.Reclus à P.Pelet, 28 mai 1884.

5. BNF, NAF, 16798, f.77, Lettre d'É.Reclus à P.Pelet, 28 mai 1884.

6. BNF, NAF, 16798, f. 77, Lettre d'É. Reclus à P. Pelet, 21 juin1884.

7. Centro Internacional de Pesquisas sobre Anarquismo (Centre international de recherches sur l'Anarchisme [CIRA]), Jacques Gross Papers, lettre d'E. Reclus à J. Gross, 7 avril 1887.

\section{RESUMOS}

Em seu trabalho enciclopédico Nouvelle Géographie Universelle (1876-1894), o anarquista e geógrafo Élisée Reclus (1830-1905) tentou enfatizar a ideia de uma comunhão universal e fraternal entre os povos do mundo. Reclus era famoso não somente como geógrafo, mas também como exilado da Comuna de Paris. Atualmente, pesquisadores não são unânimes na apreciação da relação entre a Nouvelle Géographie Universelle e o colonialismo contemporâneo, mas poucos deles leram todos os dezenove volumes que a compõem. Neste artigo, abordaremos dois casos emblemáticos: o domínio inglês na Índia e a ocupação francesa na Argélia tal como apresentados na Nouvelle Géographie Universelle. Intentaremos demonstrar que esta obra não-convencional é um recurso interessante e radical para os que trabalham na construção de um discurso crítico sobre Europa, diferença e colonialismo.

Le géographe anarchiste Élisée Reclus (1830-1905) a affirmé l'idée de la fraternité universelle de tous les peuples du monde dans son travail encyclopédique Nouvelle Géographie universelle (NGU) (1876-1894). Les arguments de Reclus, et ses représentations de l'Europe, de l'Ailleurs et du colonialisme, cependant, sont encore au centre d'un ébat parmi les géographes sur leur contribution éventuelle aux études actuelles sur colonialisme et post-colonialisme. Dans cet article nous analysons deux cas emblématiques, la domination anglaise sur l'Inde et l'occupation française de l'Algérie, tels que Reclus les présente dans son ouvrage majeur, en interrogeant l'analyse reclusienne de l'impérialisme et sa critique des pouvoirs coloniaux. Notre but est là de démontrer que la NGU, loin d'être un travail de géographie conventionnelle, est au contraire une ressource très importante pour la construction d'un discours autre sur l'Europe, l'Ailleurs et le colonialisme.

The anarchist and geographer Élisée Reclus (1830-1905) argued for the idea of universal brotherhood for all the peoples of the world in his encyclopedic work the Nouvelle Géographie Universelle (1876-1894). The nature of Reclus' argument and its representations of Europe, otherness and colonialism, however, are contested today, and it is unclear what insights it might offer to contemporary students of colonialism and post-colonialism. In this paper I engage with two emblematic cases-British rule over India and French occupation of Algeria-as they are presented in the NGU, considering Reclus' analysis of imperialism and his novel critique of 
colonial power. In doing so I wish to demonstrate that far from being conventional, the NGU is a radical and interesting resource for those struggling to construct a critical discourse on Europe, otherness and colonialism.

En su trabajo enciclopédico Nouvelle Géographie Universelle (1876-1894), el anarquista y geógrafo Élisée Reclus (1830-1905) intentó enfatizar la idea de una comunión universal y fraternal entre los pueblos del mundo. Reclus era famoso no sólo como geógrafo si no también como exiliado de la Comuna de París. Actualmente los investigadores no tienen unanimidad sobre la relación entre la Nouvelle Géographie Universelle y el colonialismo contemporáneo, pero, pocos leyeron los diecinueve volúmenes que la componen. En este artículo abordaremos dos casos emblemáticos: el dominio inglés en la India y la ocupación francesa en Argelia tal y como son presentados en Nouvelle Géographie Universelle. Intentaremos demostrar que esta obra no convencional es un recurso interesante y radical para los que trabajan en la construcción de un discurso crítico sobre Europa, diferencia y colonialismo.

\section{ÍNDICE}

Mots-clés: Reclus, géographie universelle, colonialisme, anarchisme, études postcoloniales Palavras-chave: Reclus, geografia universal, colonialismo, anarquismo, estudos pós-coloniais Palabras claves: Reclus, geografía universal, colonialismo, anarquismo, estudios pos-coloniales Keywords: Reclus, universal geography, colonialism, anarchism, postcolonial studies

\section{AUTOR}

\section{FEDERICO FERRETTI}

Pesquisador do Departamento de Geografia e Meio Ambiente, Universidade de Genebra. Integrante do Laboratório Política, Epistemologia e História da Geografia(LAPEHGE/UFRRJ).

Email: Federico.Ferretti@unige.ch 